\title{
Adipose tissue loss in adjuvant arthritis is associated with a decrease in lipogenesis, but not with an increase in lipolysis
}

\author{
A I Martín, E Castillero, M Granado, M López-Menduiña, M A Villanúa and A López-Calderón \\ Department of Physiology, Faculty of Medicine, University Complutense of Madrid, 28040 Madrid, Spain \\ (Correspondence should be addressed to A López-Calderón; Email: alc@med.ucm.es)
}

\begin{abstract}
Adjuvant-induced arthritis is a model of rheumatoid arthritis that induces cachexia. In other cachectic situations, there is an increase in lipolysis resulting in a loss of adipose tissue mass. The aim of this work was to analyse the effect of chronic arthritis, induced by adjuvant injection, on white adipose tissue (WAT). For this purpose, rats were killed 10 days after adjuvant injection, when the first external symptoms appeared, on days 15 and 22 when the external signs of the illness reach their severest level. As arthritis decreases food intake, a pair-fed group was also included. Serum concentrations of insulin, leptin, adiponectin, glycerol and nitrites, as well as gene expression of leptin, adiponectin, hormonesensitive lipase (HSL), fatty acid synthase (FAS), tumour necrosis factor $\alpha$ and zinc- $\alpha_{2}$-glycoprotein (ZAG) were
\end{abstract}

determined. Arthritis decreased food intake between days 5 and 16, but not during the last 5 days of the experiment. There was a marked decrease in relative adipose tissue weight and in serum leptin and adiponectin as well as in their gene expression in WAT in arthritic rats. Arthritis decreased the gene expression of FAS in the WAT. However, none of these effects was found in pair-fed rats. Arthritis did not increase lipolysis, since arthritic rats have lower serum concentrations of glycerol, HSL mRNA in WAT, as well as liver ZAG mRNA than the pair-fed or control rats. These data suggest that in chronic arthritis the decrease in white adipose mass is secondary to a reduced adipose lipogenesis, and this effect is not mainly due to the decrease in food intake.

Journal of Endocrinology (2008) 197, 111-119

\section{Introduction}

Cachexia is characterized by a marked decrease in body weight and a progressive decrease in adipose tissue and skeletal muscle mass. This debilitating response occurs in many chronic diseases, such as cancer, heart or renal failure, diabetes, as well as in inflammatory diseases such as Crohn's disease, sepsis and rheumatoid arthritis. Rheumatoid arthritis patients have hypermetabolism and accelerated protein breakdown (Roubenoff et al. 1994), and it has been postulated that rheumatoid cachexia is an important contributor in increasing morbidity and premature mortality in those patients (Walsmith et al. 2004).

Adjuvant-induced arthritis is a well-established model of rheumatoid arthritis that can be induced in rats by an intradermal injection of Freund's adjuvant. Ten days after adjuvant injection, rats start to lose body weight even before the external signs of the illness are manifested (López-Calderón et al. 1999). On day 22 after adjuvant injection, when the external signs of the illness reach their severest level, the decrease in body weight in arthritic rats is associated with a marked decrease in skeletal muscle and white adipose tissue (WAT) mass (Granado et al. 2006).

Muscle wasting in experimental arthritis, as well as in other inflammatory illnesses, seems to be due to enhanced protein breakdown by the ubiquitin-proteasome proteolytic pathway (Lecker et al. 2004, Granado et al. 2005b). However, the mechanism by which chronic inflammation reduces fat stores is not well known. Fat mass loss can be secondary to an increase in lipolysis and/or a decrease in lipogenesis. Lipolysis in WAT is under hormonal control, where the hormonesensitive lipase (HSL) is the main regulatory pathway in rodent lipolysis (Holm 2003). In cancer cachexia, both lipolysis and HSL gene expression are increased in rodents and humans (Tisdale 2004, Agustsson et al. 2007).

Zinc- $\alpha_{2}$-glycoprotein $(Z A G)$ is a lipid mobilizing protein that has also been proposed to be one of the causes of cachexiainduced WAT loss (Sanders \& Tisdale 2004). ZAG stimulates adipocyte adenyl cyclase, induces lipolysis and decreases body weight (Russell et al. 2004). In vivo ablation of ZAG induces an increase in body weight that correlates with a reduction in adipocyte lipolysis (Rolli et al. 2007). ZAG is expressed ubiquitously but it is mainly expressed in the rodent liver (Rolli et al. 2007). This protein is overexpressed by several tumours (Todorov et al. 1998), and its mRNA is increased in WAT and in the liver of mice with tumour-induced cachexia (Bing et al. 2004). For these reasons, increased gene expression of ZAG has been related with cachexia.

In the present study, we examined the effect of chronic arthritis on visceral WAT mass regulation. Serum concentrations 
ofleptin and adiponectin as well as their gene expression in WAT were measured as they are the main adipokines released by the adipose tissue. As lipolytic factors, HSL and ZAG gene expression as well as serum concentration of glycerol were determined. To evaluate whether decreased lipogenic capacity could play a role in arthritis-induced decrease in body weight, we measured the expression offatty acid synthase (FAS) in WAT, since this enzyme plays a central role in the novo lipogenesis in mammals.

\section{Materials and Methods}

\section{Experimental design}

Arthritic and control male Wistar rats were purchased from Charles River (Barcelona, Spain). Arthritis was induced in the rats by an intradermal injection of $1 \mathrm{mg}$ heat-inactivated Mycobacterium butyricum in the right paw (day 0). Control animals were injected with mineral oil. After arriving (day 3 after adjuvant injection), rats were housed 3-4 per cage, and maintained under standardized conditions of temperature $\left(20-22^{\circ} \mathrm{C}\right.$ ) and light (lights on from 0730 to $\left.1930 \mathrm{~h}\right)$. The procedures followed the guidelines recommended by the EU for the care and use of laboratory animals and were approved by the Complutense University animal care committee.

The effect of arthritis on visceral adipose tissue was studied in different stages of the illness, when rats started to develop external signs of inflammation (day 10 after adjuvant injection) and when the illness was established (days 15 and 22). Body weight, food intake and the arthritis index scores were examined daily. Assessment of arthritis was performed by measuring the arthritis index of each animal, which was scored by grading each paw from 0 to 4 . Grading was determined as: 0 , no erythema or swelling; 1) slight erythema or swelling of one or more digits; 2) swelling of paw; 3) swelling of entire paw and the ankle; and 4) ankylosis, incapacity to bend the ankle. The severity score was the sum of the clinical scores of each limb, the maximum value being 16. On days 10, 15 and 22, eight control and ten arthritic rats were killed by decapitation between 1200 and $1300 \mathrm{~h}$. As arthritis decreases food intake, a control group of eight rats that received the same amount of food (g/100 g bw) eaten by the arthritic rats (pair-fed group) was also included.
Food intake per cage was calculated by measuring the difference between the initial and the remaining amount of pellets in the feeder, and expressed as g per rat per $100 \mathrm{~g}$ body weight. The same amount of food consumed by the arthritic rats was given to the pair-fed group the following day. At the end of the experiment, on day 22 after adjuvant injection, pair-fed rats were also killed by decapitation between 1200 and $1300 \mathrm{~h}$. All rats were killed in a separate room, within $30 \mathrm{~s}$ after being removed from their cages. Trunk blood was collected in cooled tubes, allowed to clot, centrifuged and the serum was stored at $-20{ }^{\circ} \mathrm{C}$ until insulin, leptin, glucose and glycerol assays were performed. Immediately after decapitation, spleen and epididymal WAT were weighted. The epididymal WAT and the liver were dissected, frozen in liquid nitrogen and stored at $-80^{\circ} \mathrm{C}$ until RNA extraction.

\section{Real-time PCR}

RNA was extracted by the guanidine thiocyanate method using a commercial kit (Ultraspec RNA, Biotecx Laboratories Inc., Houston, TX, USA). The integrity of the RNA was confirmed using agarose gel electrophoresis. For RT-PCR analysis, $1 \mu \mathrm{g}$ WAT or liver total RNA was reverse transcribed with Quantiscript Reverse Transcription kit (Qiagen Combh Hilden). Primers for PCR (Table 1) were obtained from Roche (Madrid, Spain) using the EXIQON Universal Probe Library (leptin, HSL, FAS, ZAG, adiponectin) or from previously published sequences of tumour necrosis factor- $\alpha$ (TNF- $\alpha$; Dehoux et al. 2004) and hypoxanthine-guanine phosphoribosyltransferase (HPRT; Peinnequin et al. 2004). Primers were designed to span a single sequence derived from two exons (i.e. separated by an intron in genomic DNA and primary RNA transcripts to minimize amplification).

Each real-time PCR consisted of $10 \mathrm{ng}$ total RNA equivalents, $1 \times$ Takara SYBR Green Premix Ex Taq (Takara Bio Inc., Otsu, Shiga, Japan) and $300 \mathrm{nM}$ forward and reverse primers in a reaction volume of $25 \cdot 5 \mu \mathrm{l}$. Reactions were carried out on a SmartCycler (Cepheid, Sunnyvale, CA, USA).

Parameters included an initial activation of hotStarTaq DNA polymerase at $95^{\circ} \mathrm{C}$ for $15 \mathrm{~s}$, followed by 40 cycles of denaturation at $94{ }^{\circ} \mathrm{C}$ for $15 \mathrm{~s}$, annealing at $60{ }^{\circ} \mathrm{C}$ and extension at $72{ }^{\circ} \mathrm{C}$ for $30 \mathrm{~s}$. Specific amplification was confirmed by the presence of one single peak in the melting

Table 1 Primers for real-time PCR

Forward primer $\left(5^{\prime}-3^{\prime}\right)$

Gene
TNF- $\alpha$
Leptin
Adiponectin
ZAG
HSL
FAS
HPRT

GCCACCAGCTCTTCTGTCT CCAGGATCAATGACATTTCACA TGGTCACAATGGGATACCG CCTGCAGTCCTTCAGGAGAC TATCCGCTCTCCGGTTGA GGCCACCTCAGTCCTGTTAT CTCATGGACTGATTATGGACAGGAC
Reverse primer $\left(5^{\prime}-3^{\prime}\right)$

Product (bp)

$\begin{array}{lr}\text { GTCTGGGCCATGGAACTGAT } & 100 \\ \text { AATGAAGTCCAAACCGGTGA } & 71 \\ \text { CCCTTAGGACCAAGAACACCT } & 93 \\ \text { AATGCGGTGGCTTGA } & 101 \\ \text { CGAGCACTGGAGGAGTGTTT } & 81 \\ \text { AGGGTCCAGCTAGAGGGTACA } & 60 \\ \text { GCAGGTCAGCAAAGAACTTATAGCC } & 122\end{array}$


curve plots. In addition, the PCR products were analysed by agarose gel electrophoresis. Results were calculated as per cent of control rats, using the cycle threshold $2^{\left(\Delta \Delta C_{t}\right)}$ method (Livak \& Schmittgen 2001) with the HPRT as reference gene.

\section{Serum determinations}

Nitrite and nitrate concentrations in serum were measured by a modified method of Griess assay, described by Miranda et al. (2001). Serum was deproteinized to reduce turbidity by centrifugation through a $30-\mathrm{kDa}$ molecular mass filter using a Centrifree Micropartition Device with a YM-30 ultrafiltration membrane (Amicon Division, Millipore Corporation, Bedford, TX, USA), at 15000 r.p.m. for $1 \mathrm{~h}$ at $37^{\circ} \mathrm{C}$ for $300 \mu \mathrm{l}$ samples. Mixing of $100 \mu \mathrm{l}$ filtrated serum with $100 \mu \mathrm{l}$ vanadium chloride was carried out and was quickly followed by the addition of the Griess reagents. The determination was performed after incubation at $37^{\circ} \mathrm{C}$ for $30 \mathrm{~min}$. The absorbance was measured at $540 \mathrm{~nm}$. Nitrite and nitrate concentrations were calculated using a $\mathrm{NaNO}_{2}$ standard curve and expressed as percentage of the control group.

Serum concentrations of rat leptin and adiponectin were determined by RIA and ELISA using commercial kits from Linco Research Inc. (St Charles, MO, USA) and B-Bridge International Inc. (Otsuka Pharmaceuticals, Japan), following the manufacturer's instructions. Insulin was measured by RIA that has been previously described (Vara \& Tamarit-Rodriguez 1988).

Glycerol and glucose levels were determined according to their respective protocol kits (Sigma; and Infinity Glucose Oxidase, Thermo Electron, Louisville, CO, USA).

\section{Statistical analysis}

All data are presented as the mean \pm s.E.M. Comparisons between means were made by one-way ANOVA and subsequent LSD multiple range test. Because there were no significant differences between data obtained in the control rats killed 10, 15 or 22 days after vehicle injection, they were used as one control group. The TNF- $\alpha$ mRNA data were subjected to $\log$ transformation, since variances showed a log-normal distribution. A value of $P<0 \cdot 05$ was considered significant.

\section{Results}

The arthritis index scores, left paw volume and serum concentrations of nitrite + nitrate are shown in Fig. 1. During the first phase of the illness, until day 10 after adjuvant injection, arthritic rats had a small inflammatory reaction in the injected paw, with arthritis scores between 2 and 3 (Fig. 1A), whereas in the non-injected paw (left paw) the paw volume of the arthritic rats was similar to that of control or pair-fed rats (Fig. 1B). On day 10 the poly-articular inflammation started, reaching the maximum value of arthritis scores (14.7) on days 21 and 22. Coinciding with the increase in the arthritis index score, on days 15 and 22, arthritic rats had higher paw volume $(P<0 \cdot 01)$ than
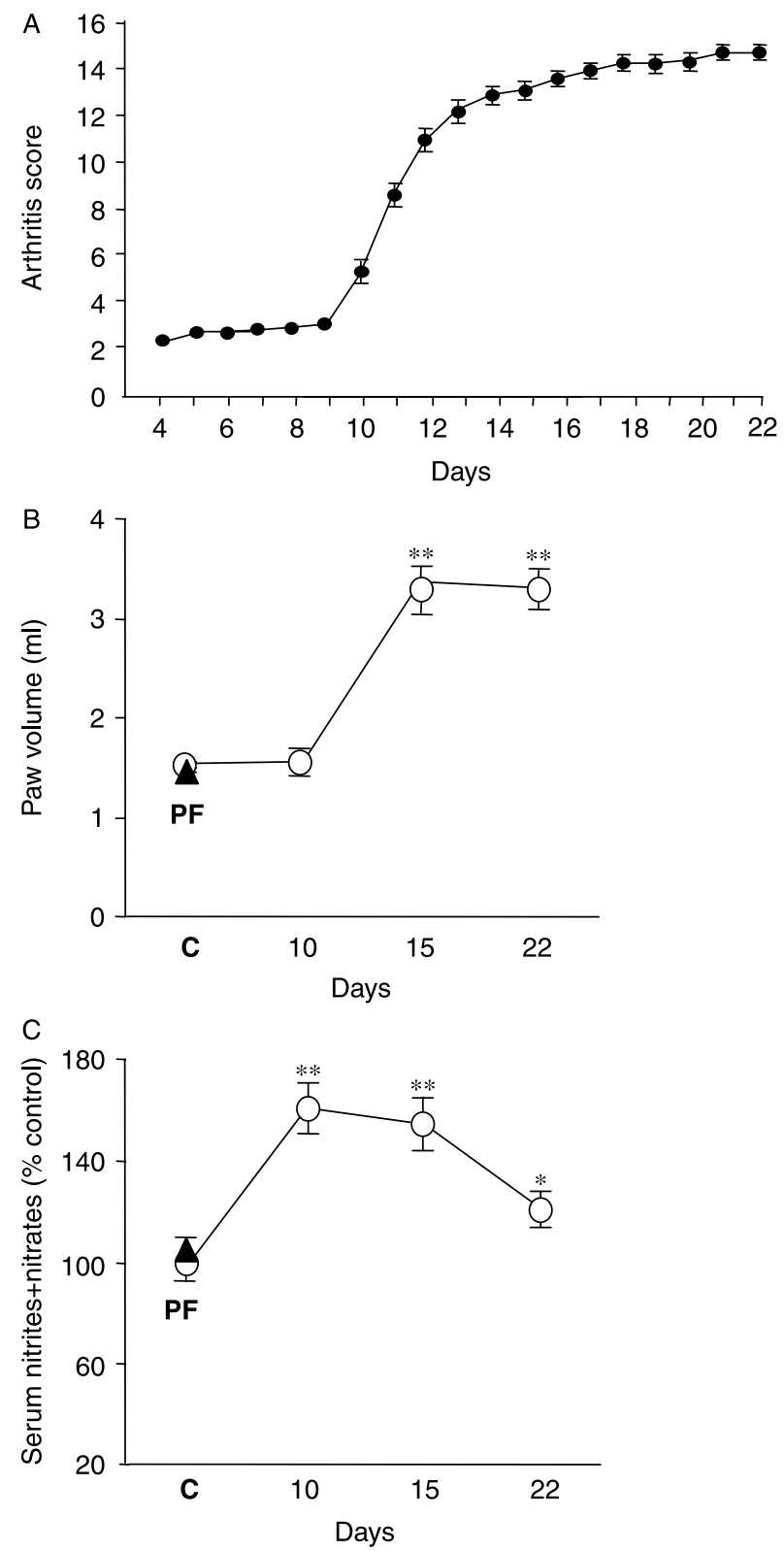

Figure 1 (A) Arthritis index score evolution from day 4 to 22 after adjuvant injection, (B) left paw volume and (C) serum concentrations of nitrites + nitrates in control rats fed 'ad libitum' (C), pairfed rats (PF, black triangle) and in arthritic rats 10,15 and 22 days after adjuvant injection. Arthritis increased the left paw volume $\left(F_{4,49}=81, P<0 \cdot 01\right)$ and the serum nitrite + nitrate levels $\left(F_{4,47}=14, P<0 \cdot 01\right)$. Values shown are the mean \pm S.E.M. ( $n=8-16$ rats). ${ }^{*} P<0 \cdot 05,{ }^{* *} P<0 \cdot 01$ versus control rats.

control rats (Fig. 1B). Pair-fed rats had a paw volume similar to that of control rats. Arthritis increased the serum concentrations of nitrites + nitrates $(P<0 \cdot 01)$ having the highest levels on day 10 after adjuvant injection (Fig. 1C). On day 22, the serum concentrations of nitrites + nitrates were between those observed on day 10 and in control rats. 
Figure 2 shows body weight and the daily food intake from day 4 to 22 after adjuvant injection, as well as spleen and epididymal WAT weights. Arthritic rats had lower body weight than controls from day 5 (Fig. 2A), but on day 10, when the external signs of arthritis started to dramatically increase, the body weight gain in the arthritic rats was even lower than before. Between days 5 and 15, the arthritic rats ate less food than controls (Fig. 2B). The decrease in body weight in the arthritic rats is not only due to the lower food intake but also due to the fact that pair-fed rats had higher body weight than arthritic rats $(P<0 \cdot 01)$. In addition, during the last 5 days of the experiment (days 18-22), arthritic rats ate similar amounts to control rats, but the increase in body weight was lower in arthritic rats than in control or pair-fed rats (Fig. 2A). The spleen weight increased $(P<0 \cdot 01)$ in the arthritic rats from day 10 after adjuvant injection (Fig. 2C) and continued increasing on days 15 and 22. In contrast, arthritis decreased the relative weight of the epididymal WAT in all the days studied $(P<0 \cdot 01)$ in the arthritic rats, whereas no differences were observed between control and pair-fed rats (Fig. 2D). Epididymal WAT weight, in the arthritic rats, progressively decreased on days 10 and 15, and the values on day 22 were similar to those on day 15 .

Arthritis decreased $(P<0 \cdot 05)$ the serum concentrations of insulin on days 10 and 15; however, on day 22, the serum concentrations of insulin were similar to those of control rats (Fig. 3A). The serum concentrations of glucose were not modified by arthritis (data not shown). Arthritis also decreased the serum concentrations of leptin and adiponectin on all the days analysed $(P<0 \cdot 01$, Fig. 3B and C). The pair-fed rats have similar serum concentrations of insulin and leptin, but higher serum adiponectin than control rats.

In the arthritic rats, TNF- $\alpha$ expression in WAT was already increased from day $10(P<0 \cdot 05)$ and throughout the rest of the days studied (Fig. 4A). In contrast, leptin gene expression in the epididymal WAT was decreased in arthritic rats to very low levels, 20-30\% of control values, in all the days analysed (Fig. 4B). Arthritis also decreased gene expression of adiponectin and FAS in the epididymal WAT on days 10 and $15(P<0 \cdot 01$, Fig. $4 \mathrm{C}$ and D). On day 22, FAS and adiponectin mRNA were higher than before, but still lower
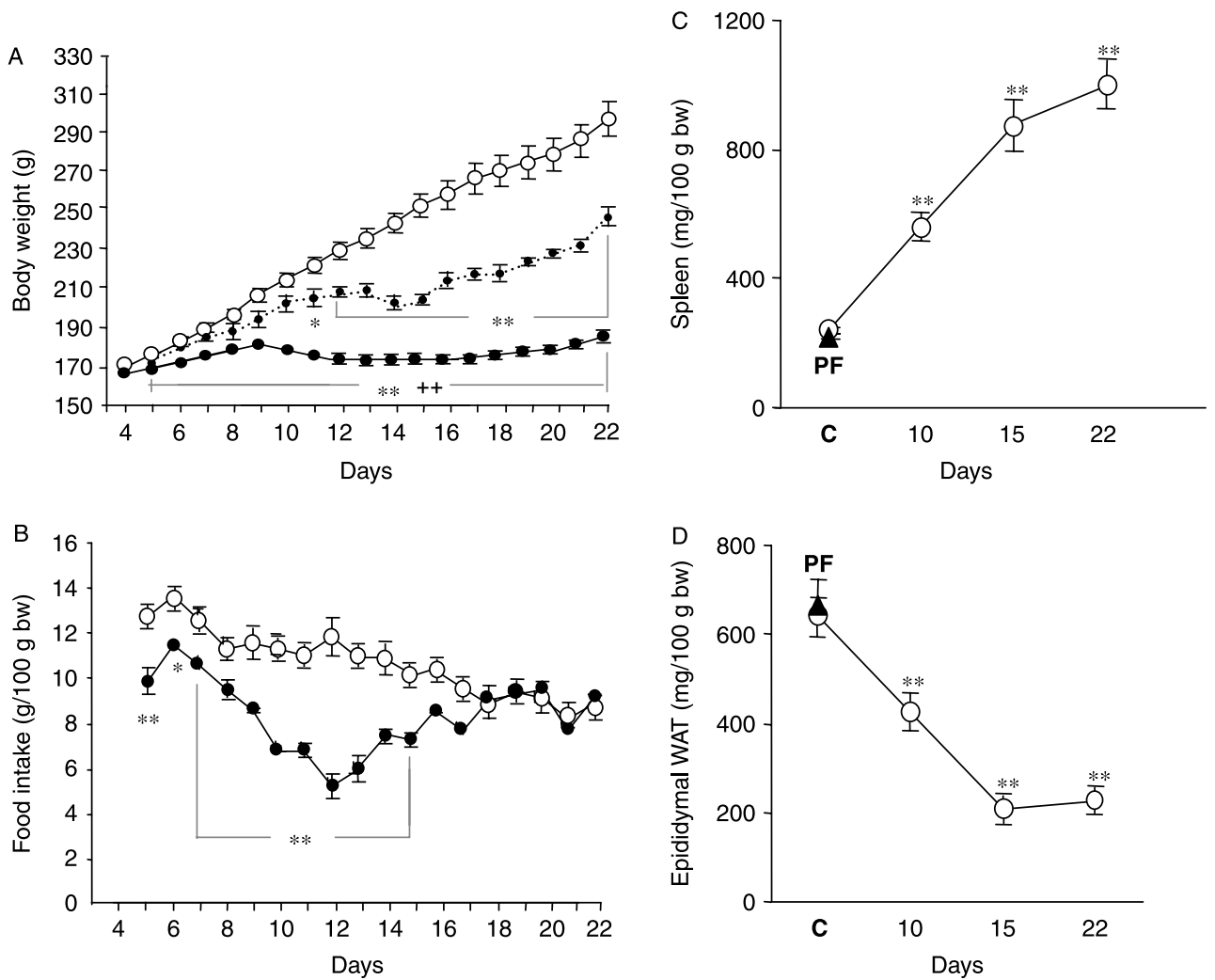

Figure 2 (A) Body weight and (B) daily food intake evolution from day 4 to 22 after adjuvant injection in control rats (open circles, continuous line), arthritic rats (black circles, continuous line) and pair-fed rats (black circles, dotted line). (C) Relative weight of spleen and (D) epididymal white adipose tissue (WAT) in control rats fed ' $a d$ libitum' $(\mathbf{C})$, pair-fed rats (PF, black triangle) and in arthritic rats 10, 15 and 22 days after adjuvant injection. Arthritis decreased food intake $\left(F_{1,187}=116, P<0 \cdot 01\right)$, body $\left(F_{2,742}=406, P<0 \cdot 01\right)$ and WAT weight $\left(F_{4,47}=29, P<0 \cdot 01\right)$, whereas it increased spleen weight $\left(F_{4,49}=52, P<0 \cdot 01\right)$. Values shown are the mean \pm S.E.M. $\left(n=8-16\right.$ rats), one-way ANOVA and LSD multiple comparison test. ${ }^{*} P<0 \cdot 05, * * P<0 \cdot 01$ versus control rats, ${ }^{++} P<0 \cdot 01$ versus pair-fed rats. 

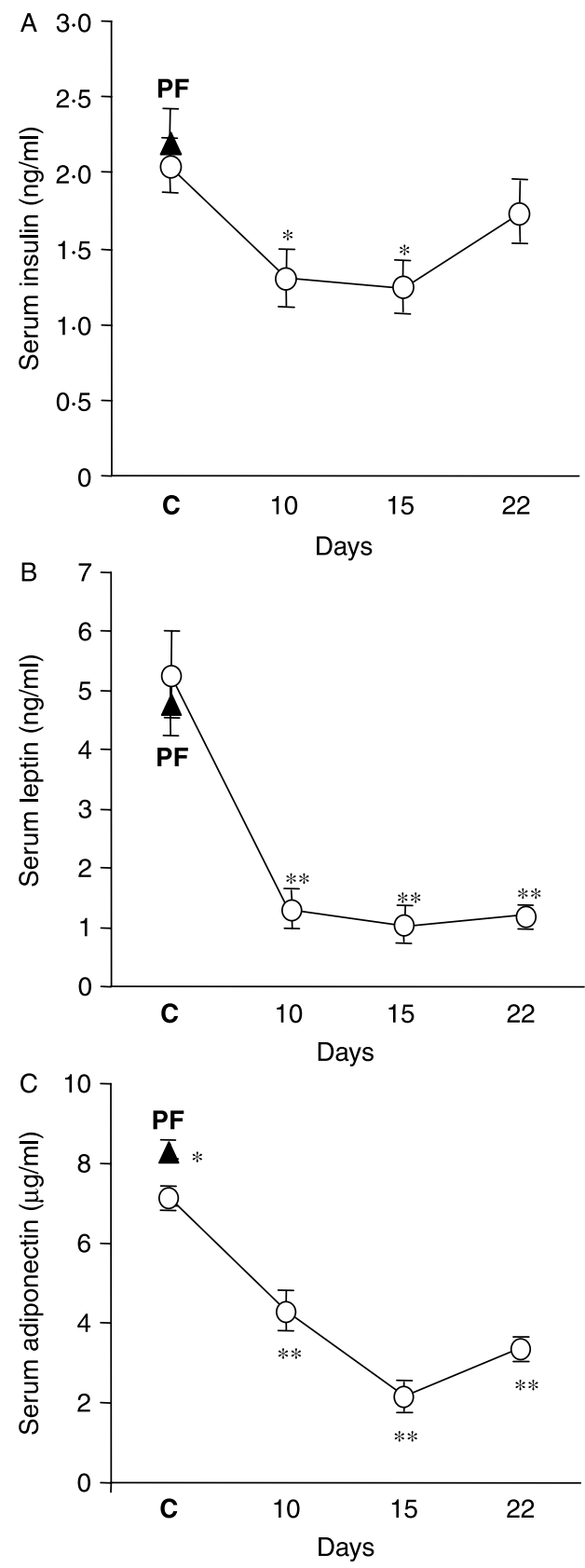

Figure 3 Serum concentrations of (A) insulin, (B) leptin and (C) adiponectin in control rats fed 'ad libitum' (C), pair-fed rats (PF, black triangle) and in arthritic rats 10, 15 and 22 days after adjuvant injection. Arthritis decreased the serum concentrations of insulin $\left(F_{4,48}=4 \cdot 4, P<0 \cdot 01\right)$, leptin $\left(F_{4,49}=17, P<0 \cdot 01\right)$ and adiponectin $\left(F_{4,48}=64, P<0 \cdot 01\right)$. Values shown are the mean \pm S.E.M. ( $n=8-16$ rats), one-way ANOVA and LSD multiple comparison test. ${ }^{*} P<0 \cdot 05,{ }^{* *} P<0 \cdot 01$ versus control rats.

than in the control rats. The pair-fed rats had lower leptin mRNA in the epididymal WAT than the control rats $(P<0 \cdot 05)$, but both groups of non-arthritic rats had similar adiponectin and FAS mRNA in epididymal WAT.
HSL mRNA was decreased in arthritic rats $(P<0 \cdot 05)$, but the decrease was significant only on day 15 after adjuvant injection (Fig. 5A). Arthritis decreased the serum concentration of glycerol, but this decrease was significant $(P<0 \cdot 05)$ only on day 22 (Fig. 5B). In pair-fed rats, HSL gene expression in WAT and serum concentrations of glycerol were similar to those of control rats. The effect of arthritis on ZAG gene expression was analysed in the epididymal WAT as well as in the liver (Fig. 5C and D). The ZAG mRNA in the epididymal WATwas not modified in pair-fed or arthritic rats on any of the days studied. In contrast, the ZAG mRNA in the liver of arthritic rats was decreased on days 15 and 22 (Fig. 5).

\section{Discussion}

Adjuvant-induced arthritis decreased visceral WAT weight as well as food intake. However, the decrease in visceral WAT weight in arthritic rats is higher than the decrease in body weight and food intake. Moreover, the pair-fed rats have lower body weight than the control rats, but had similar relative WAT weight to the control rats. These results indicate that arthritis-induced decrease in WAT weight is not only due to a decrease in food intake, but also related to metabolic alterations that result in a dramatic decrease of adiposity.

Among all factors studied in serum or in WAT, pair-feeding the rats only decreased the gene expression of leptin, although serum concentrations of leptin were not modified. A similar decrease in leptin gene expression in WAT has been recently reported in pair-fed mice of a cancer cachexia model without severe anorexia (Bing et al. 2006). Although the pair-fed and arthritic rats had similar food intake to the control rats between days 18 and 22, their leptin gene expression in WAT is lower than that in the control group. These data suggest that leptin gene expression is very sensitive to the total WAT mass, rather than to the caloric intake.

The decrease in serum leptin and its gene expression in arthritic rats has previously been described in different models of experimental arthritis (Hultgren \& Tarkowski 2001, Granado et al. 2005a, Stofkova et al. 2006). A decrease in leptin secretion has also been reported in humans with other chronic inflammatory illnesses, such as tuberculosis or inflammatory bowel disease (van Crevel et al. 2002, Karmiris et al. 2006). Furthermore, long-term incubation with cytokines inhibits leptin mRNA and leptin release from adipocytes (Bruun et al. 2002). The cause of leptin decrease in arthritic rats can be a combination of two factors: the decrease in adipose mass and chronic inflammation. In contrast, the effect of rheumatoid arthritis on leptin is not well known, since contradictory data have been reported. Both a decrease and an increase in serum concentrations of leptin in rheumatoid arthritis patients have been reported (Tokarczyk-Knapik et al. 2002, Otero et al. 2006). An inverse correlation between plasma leptin and the degree of inflammation in rheumatoid arthritis patients has also been reported (Popa et al. 2005). However, most researchers find a correlation between the leptin and the body mass index in 

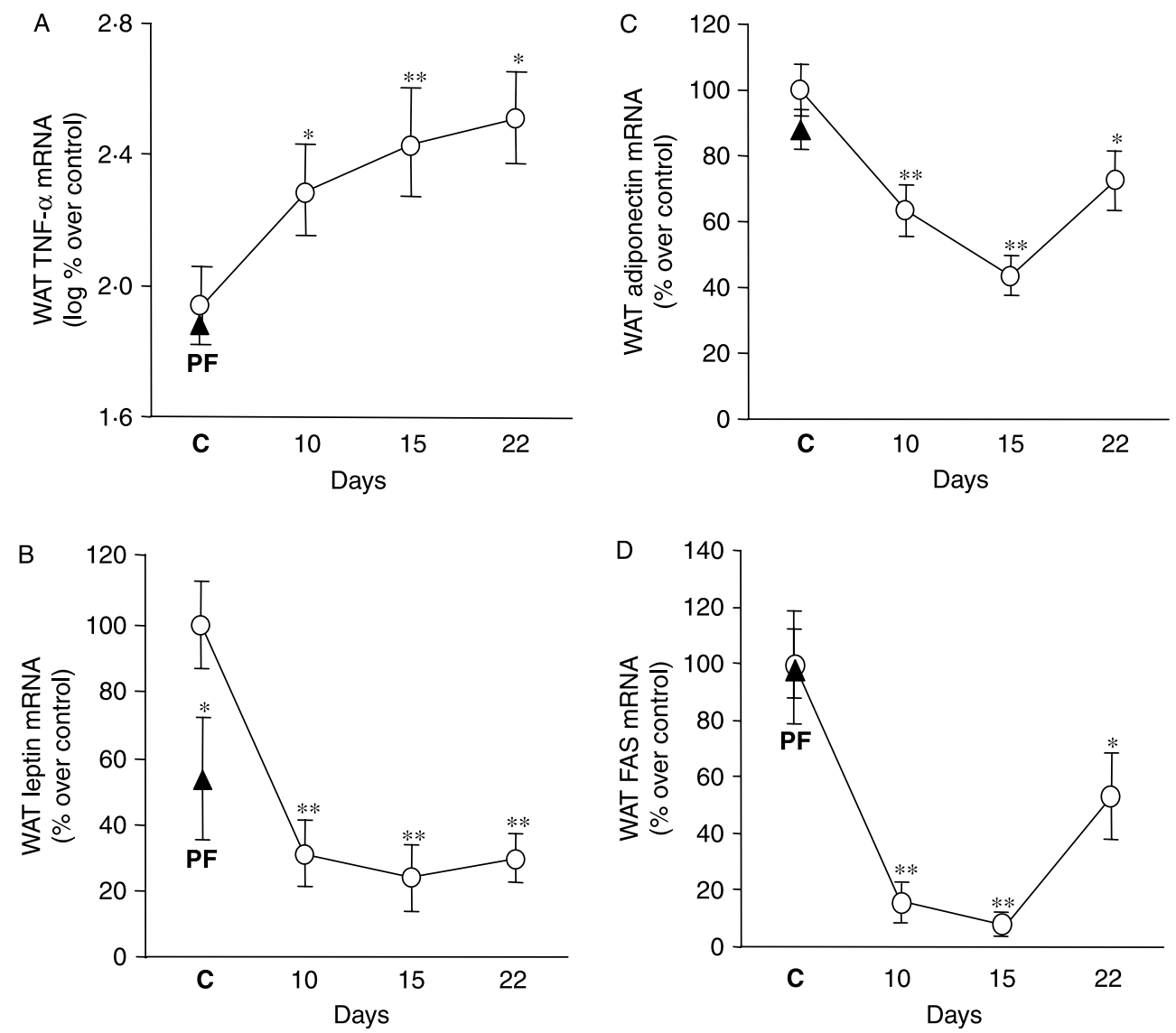

Figure 4 (A) TNF- $\alpha$, (B) leptin, (C) adiponectin and (D) FAS gene expression in WAT, in control rats fed 'ad libitum' (C), pair-fed rats (PF, black triangle) and in arthritic rats 10, 15 and 22 days after adjuvant injection. The mRNAs were measured by real-time PCR as described in Materials and Methods, and results are expressed as percentage of the control rats. Arthritis increased TNF- $\alpha$ mRNA levels in WAT $\left(F_{4,47}=5 \cdot 2\right.$, $P<0 \cdot 01)$, whereas it decreased those of leptin $\left(F_{4,46}=7 \cdot 4, P<0 \cdot 01\right)$, adiponectin $\left(F_{4,48}=64, P<0 \cdot 01\right)$ and FAS $\left(F_{4,43}=11, P<0 \cdot 01\right)$. Values shown are the mean \pm s.E.M. $(n=8-16$ rats), one-way ANOVA and LSD multiple comparison test. ${ }^{*} P<0 \cdot 05, * * P<0 \cdot 01$ versus control rats.

rheumatoid arthritis patients, but not between the leptin and the disease activity (Hizmetli et al. 2007, Wislowska et al. 2007).

The time course of serum nitrite + nitrate was different to those that of arthritis scores and paw volume. As has been described previously (Connor et al. 1995, Conforti et al. 2001), serum concentrations of nitrite + nitrate were higher on days 10 and 15 than on day 22, whereas the highest level of paw inflammation and the highest arthritis scores were observed on day 22 after adjuvant injection. Similarly, arthritis-induced changes in serum concentrations of insulin and adiponectin, and gene expression of FAS, adiponectin and the HSL were more evident on day 15 than on day 22 after adjuvant injection. These data suggest that systemic inflammation, contrary to the external signs of inflammation, might be higher on day 15 than on day 22 .

The HSL is a rate-limiting enzyme of lipolysis that has been reported to be increased in other inflammatory situations such as sepsis (Sugawara et al. 2003) and cancer (Tisdale 2004). In addition, caloric restriction induces lipid mobilization through induction of HSL in visceral fat ( $\mathrm{Li}$ et al. 2003). However, adjuvant arthritis did not increase the gene expression of HSL in WAT. On the contrary, this lipase is significantly decreased on day 15 after adjuvant injection. The decrease in HSL is concomitant with the minimum relative weight of epididymal WAT. It is possible that the decrease in WAT mass in arthritic rats was secondary to an increase in the expression of the lipomobilizing protein $Z A G$, as it has been described in cancer (Bing et al. 2006). However, ZAG gene expression was decreased in the liver of arthritic rats and not modified in WAT. The decrease in ZAG mRNA in the liver occurred on days 15 and 22, when the epididymal WAT weight values were very low. Similarly, in another inflammatory situation, such as LPS administration, ZAG mRNA expression was also decreased in the liver (authors' unpublished observation).

Other data against the hypothesis that chronic arthritis increases lipolysis are the low serum concentrations of glycerol in arthritic rats. Glycerol and free fatty acids are derived from 

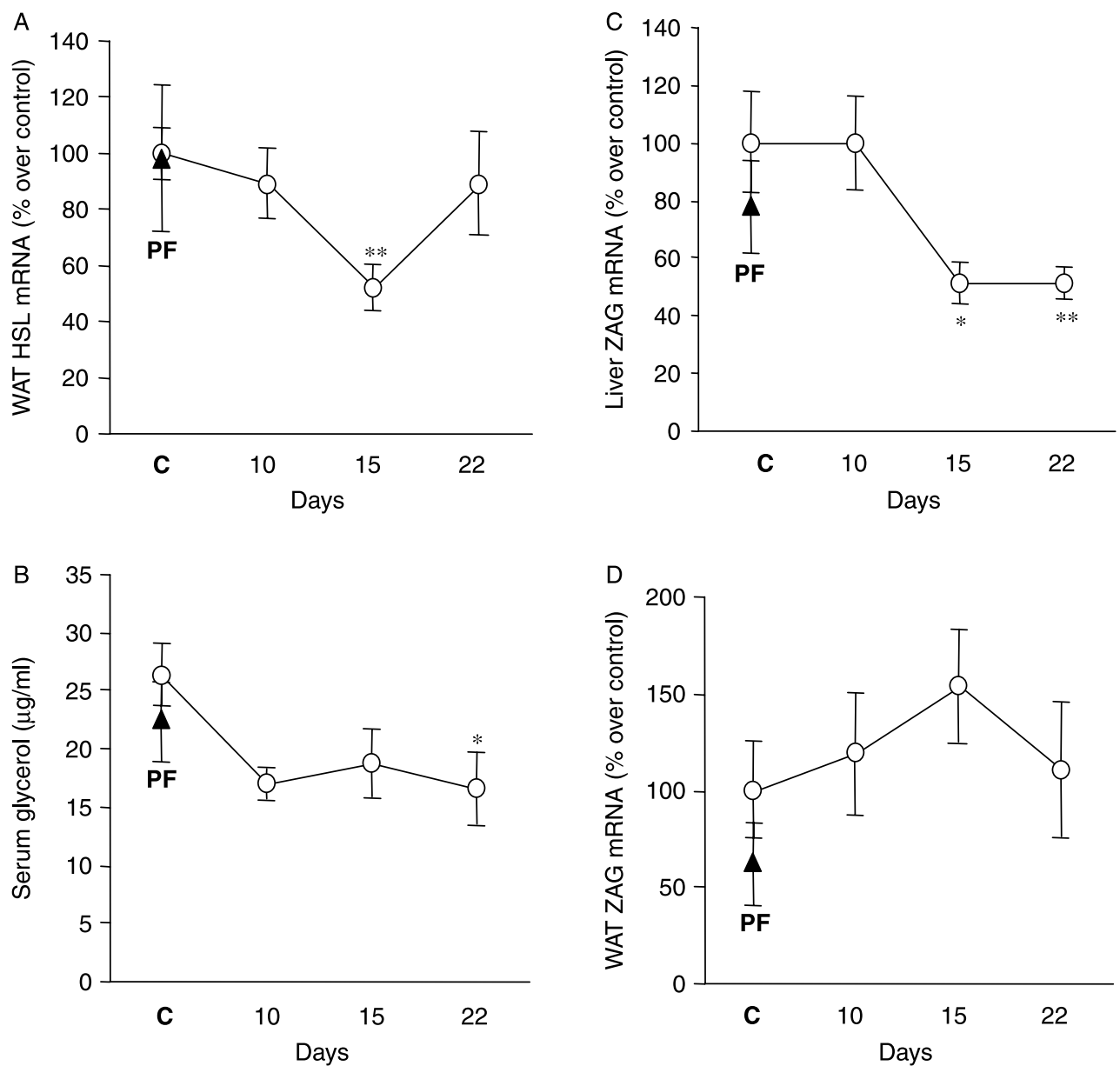

Figure 5 (A) Hormone-sensitive lipase (HSL), (B) serum concentrations of glycerol, (C) ZAG mRNA in the liver of control rats and (D) zinc- $\alpha_{2}$ macroglobulin (ZAG) mRNA in the epididymal white adipose tissue (WAT) fed 'ad libitum' (C), pair-fed rats (PF, black triangle) and in arthritic rats 10, 15 and 22 days after adjuvant injection. The HSL and ZAG mRNA were measured by real-time PCR as described in Materials and Methods, and results are expressed as percentage of the control rats fed 'ad libitum'. Arthritis decreased liver ZAG mRNA $\left(F_{4,42}=2 \cdot 9, P<0 \cdot 05\right)$. Values shown are the mean \pm s.E.M. $(n=8-16$ rats), one-way ANOVA and LSD multiple comparison test. ${ }^{*} P<0 \cdot 05,{ }^{* *} P<0 \cdot 01$ versus control rats.

triglycerides when they are hydrolysed by lipolysis. Serum glycerol levels are increased in processes such as cancer (Agustsson et al. 2007). Accordingly, serum glycerol has been measured as an index of in vivo lipolytic activity. As observed with the gene expression of the two lipolytic factors (HSL and ZAG) in arthritic rats, the serum concentrations of glycerol are not elevated, but they are decreased on day 22 after adjuvant injection. All these data suggest that arthritis does not increase lipolysis, on the contrary it seems to decrease it. Similarly, in burned rats, the atrophy of the WAT is associated with a decrease in catecholamines-induced lipolysis (Ikezu et al. 1999), and the alterations in lipid metabolism are concomitant with an increase in adipocyte apoptosis (Yasuhara et al. 2006). Between the possible factors that mediate the apoptosis response, the aforementioned authors postulated that prolonged elevation of cytokines in adipose tissue can be the cause.
Taking into account that insulin increases the gene expression of FAS (Mounier \& Posner 2006), the increase in FAS mRNA in arthritic rats on day 22, in relation to day 15 , can be secondary to the normalization in serum concentrations of insulin. Food intake is another factor that is much related with FAS gene expression. Food deprivation decreases FAS activity in WAT, whereas refeeding dramatically increases FAS activity over control values (Karbowska et al. 2001, Kochan et al. 2006). However, on day 22, the arthritic rats still had lower FAS mRNA in epididymal WAT than control rats, although their food intake during the last 5 days and the serum concentrations of insulin on day 22 were similar to those of control rats.

It has been suggested that in cancer cachexia, loss of WAT mass is related to anorexia and to a decrease in food intake, whereas skeletal muscle loss is more related with increased 
proteolysis (Fouladiun et al. 2005). This does not seem to be the case in adjuvant arthritis, since pair-fed rats, although they have lower body weight than control ad libitum fed rats, have a relative WAT weight similar to them. Although we cannot exclude that part of the inhibitory effect of arthritis on body and WAT weights can be due to anorexia, inflammatory reactions play an important role. The adiponectin data support this hypothesis. The decrease in serum concentrations of adiponectin and its gene expression in WAT does not seem to be secondary to a decrease in food intake. On the contrary, dietary energy restriction leads to an increase in adiponectin secretion (Escrivá et al. 2007, Martin et al. 2007). The inhibitory effect of arthritis on adiponectin can be due to the inflammatory response, since macrophage-derived factors inhibit adipocyte differentiation as well as adiponectin and FAS gene expression in murine and human preadipocytes (Constant et al. 2006).

A decrease in serum adiponectin in adjuvant-induced arthritis has been previously described (Haruna et al. 2007). An inverse correlation between serum adiponectin and markers of inflammation has been reported in obesity (for review see Fantuzzi (2007)). The role of adiponectin in human arthritis is a paradox, since adiponectin is increased in both synovial fluid and serum of rheumatoid arthritis patients (Schäffler et al. 2003, Otero et al. 2006, Senolt et al. 2006). At the time of blood sampling, the majority of the rheumatoid arthritis patients were treated with anti-rheumatic drugs, corticosteroids or TNF- $\alpha$ antagonist. Thus, it must be taken into account that these treatments might modify adiponectin release from adipocytes. In this sense, anti-TNF- $\alpha$ therapy increases the serum adiponectin levels in patients with rheumatoid arthritis, where adiponectin is negatively correlated with disease activity score (Komai et al. 2007).

Among pro-inflammatory cytokines, TNF- $\alpha$ has been reported to decrease adiponectin production from adipocytes (Kappes \& Löffler 2000, Simons et al. 2005). Furthermore, TNF inhibits the differentiation of human adipocyte precursor cells and also promotes the delipidation of mature fat cells (Petruschke \& Hauner 1993). This cytokine has been reported to inhibit the differentiation of new adipocytes and suppress the expression of the lipogenic enzymes such as FAS (Zhang et al. 1996, Lacasa et al. 2007). All these data suggest that in the arthritic rats, after cytokine release, adipocytes secrete less adiponectin leading to a decrease in lipid accumulation. This can be reflected in the inhibition of FAS expression and a reduction in WAT weight.

In conclusion, experimental arthritis does not increase lipolysis, but has a marked inhibitory effect on peripheral lipogenesis in visceral WAT, whereas those effects are not observed in pair-fed rats.

\section{Acknowledgements}

The authors are indebted to Antonio Carmona for technical assistance and to Christina Bickart for the English correction of the manuscript. This work was supported by a grant from Ministerio de Educación Ciencia (ABFU2006-11899/BFI), by a grant from Universidad Complutense/SantanderCentralHispano PR27/05-14055, a fellowship from Gobierno Vasco to E C (BFI06.31), and from Ministerio de Educación y Ciencia to M L-M (BES-2007-16001). The authors declare that there is no conflict of interest that would prejudice the impartiality of this scientific work.

\section{References}

Agustsson T, Ryden M, Hoffstedt J, van Harmelen V, Dicker A, Laurencikiene J, Isaksson B, Permert J \& Arner P 2007 Mechanism of increased lipolysis in cancer cachexia. Cancer Research 67 5531-5537.

Bing C, Bao Y, Jenkins J, Sanders P, Manieri M, Cinti S, Tisdale MJ \& Trayhurn P 2004 Zinc-alpha2-glycoprotein, a lipid mobilizing factor, is expressed in adipocytes and is up-regulated in mice with cancer cachexia. PNAS $1012500-2505$.

Bing C, Russell S, Becket E, Pope M, Tisdale MJ, Trayhurn P \& Jenkins JR 2006 Adipose atrophy in cancer cachexia: morphologic and molecular analysis of adipose tissue in tumour-bearing mice. British Journal of Cancer 95 1028-1037.

Bruun JM, Pedersen SB, Kristensen K \& Richelsen B 2002 Effects of proinflammatory cytokines and chemokines on leptin production in human adipose tissue in vitro. Molecular and Cellular Endocrinology 190 91-99.

Conforti A, Lussignoli S, Bertani S, Ortolani R, Cuzzolin L, Benoni G \& Bellavite P 2001 Cytokine and nitric oxide levels in a rat model of immunologic protection from adjuvant-induced arthritis. International Journal of Immunopathology and Pharmacology 4 153-160.

Connor JR, Manning PT, Settle SL, Moore WM, Jerome GM, Webber RK, Tjoeng FS \& Currie MG 1995 Suppression of adjuvant-induced arthritis by selective inhibition of inducible nitric oxide synthase. European Journal of Pharmacology 273 15-24.

Constant VA, Gagnon A, Landry A \& Sorisky A 2006 Macrophageconditioned medium inhibits the differentiation of 3T3_L1 and human abdominal preadipocytes. Diabetologia 49 1402-1411.

van Crevel R, Karyadi E, Netea MG, Verhoef H, Nelwan RH, West CE \& van der Meer JW 2002 Decreased plasma leptin concentrations in tuberculosis patients are associated with wasting and inflammation. Journal of Clinical Endocrinology and Metabolism 87 758-763.

Dehoux M, Van Beneden R, Pasko N, Lause P, Verniers J, Underwood L, Ketelslegers JM \& Thissen JP 2004 Role of the insulin-like growth factor I decline in the induction of atrogin-1/MAFbx during fasting and diabetes. Endocrinology 145 4806-4812.

Escrivá F, Gavete ML, Fermín Y, Pérez C, Gallardo N, Alvarez C, Andrés A, Ros M \& Carrascosa JM 2007 Effect of age and moderate food restriction on insulin sensitivity in Wistar rats: role of adiposity. Journal of Endocrinology 194 131-141.

Fantuzzi G 2007 Adiponectin and inflammation: consensus and controversy. Journal of Allergy and Clinical Immunology Nov 30 (Epub ahead of print).

Fouladiun M, Korner U, Bosaeus I, Daneryd P, Hyltander A \& Lundholm KG 2005 Body composition and time course changes in regional distribution of fat and lean tissue in unselected cancer patients on palliative carecorrelations with food intake, metabolism, exercise capacity, and hormones. Cancer 103 2189-2198.

Granado M, Priego T, Martín AI, Villanúa MA \& López-Calderón A 2005a Anti-inflammatory effect of the ghrelin agonist growth hormone-releasing peptide-2 (GHRP-2) in arthritic rats. American Journal of Physiology, Endocrinology and Metabolism 288 E486-E492.

Granado M, Priego T, Martín AI, Villanúa MA \& López-Calderón A $2005 b$ Ghrelin receptor agonist GHRP-2 prevents arthritis-induced increase in E3 ubiquitin-ligating enzymes MuRF1 and MAFbx gene expression in skeletal muscle. American Journal of Physiology, Endocrinology and Metabolism 289 E1007-E1014.

Granado M, Martín AI, Priego T, López-Calderón A \& Villanúa MA 2006 TNF blockade did not prevent the increase of muscular MuRF-1 and $\mathrm{MAFbx}$ in arthritic rats. Journal of Endocrinology 191 319-326. 
Haruna Y, Morita Y, Yada T, Satoh M, Fox DA \& Kashihara N 2007 Fluvastatin reverses endothelial dysfunction and increased vascular oxidative stress in rat adjuvant-induced arthritis. Arthritis and Rheumatism 56 1827-1835.

Hizmetli S, Kisa M, Gokalp N \& Bakici MZ 2007 Are plasma and synovial fluid leptin levels correlated with disease activity in rheumatoid arthritis? Rheumatology International 27 335-338.

Holm C 2003 Molecular mechanisms regulating hormone-sensitive lipase and lipolysis. Biochemical Society Transactions 31 1120-1124.

Hultgren OH \& Tarkowski A 2001 Leptin in septic arthritis: decreased levels during infection and amelioration of disease activity upon its administration. Arthritis Research 3 389-394.

Ikezu T, Yasuhara S, Granneman JG, Kraemer FB, Okamoto T, Tompkins RG \& Martyn JA 1999 A unique mechanism of desensitization to lipolysis mediated by beta(3)-adrenoceptor in rats with thermal injury. American Journal of Physiology 277 E316-E324.

Kappes A \& Löffler G 2000 Influences of ionomycin, dibutyryl_cycloAMP and tumour necrosis factor-alpha on intracellular amount and secretion of apM1 in differentiating primary human preadipocytes. Hormone and Metabolic Research 32 548-554.

Karbowska J, Kochan Z \& Swierczynski J 2001 Increase of lipogenic enzyme mRNA levels in rat white adipose tissue after multiple cycles of starvationrefeeding. Metabolism 50 734-738.

Karmiris K, Koutroubakis IE, Xidakis C, Polychronaki M, Voudouri T \& Kouroumalis EA 2006 Circulating levels of leptin, adiponectin, resistin, and ghrelin in inflammatory bowel disease. Inflammatory Bowel Diseases $\mathbf{1 2}$ $100-105$.

Kochan Z, Karbowska J \& Swierczynski J 2006 The effects of weight cycling on serum leptin levels and lipogenic enzyme activities in adipose tissue. Journal of Physiology and Pharmacology 57 (Suppl 6) 115-127.

Komai N, Morita Y, Sakuta T, Kuwabara A \& Kashihara N 2007 Anti-tumor necrosis factor therapy increases serum adiponectin levels with the improvement of endothelial dysfunction in patients with rheumatoid arthritis. Modern Rheumatology 17 385-390.

Lacasa D, Taleb S, Keophiphath M, Miranville A \& Clement K 2007 Macrophage-secreted factors impair human adipogenesis: involvement of proinflammatory state in preadipocytes. Endocrinology 148 868-877.

Lecker SH, Jagoe RT, Gilbert A, Gomes M, Baracos V, Bailey J, Price SR, Mitch WE \& Goldberg AL 2004 Multiple types of skeletal muscle atrophy involve a common program of changes in gene expression. FASEB Journal 18 39-51.

Li Y, Bujo H, Takahashi K, Shibasaki M, Zhu Y, Yoshida Y, Otsuka Y, Hashimoto N \& Saito Y 2003 Visceral fat: higher responsiveness of fat mass and gene expression to calorie restriction than subcutaneous fat. Experimental Biology and Medicine 228 1118-1123.

Livak KJ \& Schmittgen TD 2001 Analysis of relative gene expression data using real-time quantitative PCR and the $2(-$ Delta Delta $\mathrm{C}(\mathrm{T}))$ method. Methods 25 402-408.

López-Calderón A, Soto L \& Martín AI 1999 Chronic inflammation inhibits $\mathrm{GH}$ secretion and alters the serum insulin-like growth factor system in rats. Life Sciences 65 2049-2060.

Martin B, Pearson M, Kebejian L, Golden E, Keselman A, Bender M, Carlson O, Egan J, Ladenheim B, Cadet JL et al. 2007 Sex-dependent metabolic, neuroendocrine, and cognitive responses to dietary energy restriction and excess. Endocrinology 148 4318-4333.

Miranda KM, Espey MG \& Wink DA 2001 A rapid, simple spectrophotometric method for simultaneous detection of nitrate and nitrite? Nitric Oxide 5 62-71.

Mounier C \& Posner BI 2006 Transcriptional regulation by insulin: from the receptor to the gene. Canadian Journal of Physiology and Pharmacology 84 713-724.

Otero M, Lago R, Gomez R, Lago F, Dieguez C, Gómez-Reino JJ \& Gualillo O 2006 Changes in plasma levels of fat-derived hormones adiponectin, leptin, resistin and visfatin in patients with rheumatoid arthritis. Annals of the Rheumatic Diseases 65 1198-1201.

Peinnequin A, Mouret C, Birot O, Alonso A, Mathieu J, Clarencon D, Agay D, Chancerelle Y \& Multon E 2004 Rat pro-inflammatory cytokine and cytokine related mRNA quantification by real-time polymerase chain reaction using SYBR green. BMC Immunology 5 3-10.
Petruschke T \& Hauner H 1993 Tumor necrosis factor-alpha prevents the differentiation of human adipocyte precursor cells and causes delipidation of newly developed fat cells. Journal of Clinical Endocrinology and Metabolism $\mathbf{7 6}$ 742-747.

Popa C, Netea MG, Radstake TR, van Riel PL, Barrera P \& van der Meer JW 2005 Markers of inflammation are negatively correlated with serum leptin in rheumatoid arthritis. Annals of the Rheumatic Diseases 64 1195-1198.

Rolli V, Radosavljevic M, Astier V, Macquin C, Castan-Laurell I, Visentin V, Guigné C, Carpéné C, Valet P, Gilfillan S et al. 2007 Lipolysis is altered in MHC class I zinc-alpha(2)-glycoprotein deficient mice. FEBS Letters 581 394-400.

Roubenoff R, Roubenoff RA, Cannon JG, Kehayias JJ, Zhuang H, DawsonHughes B, Dinarello CA \& Rosenberg IH 1994 Rheumatoid cachexia: cytokine-driven hypermetabolism accompanying reduced body cell mass in chronic inflammation. Journal of Clinical Investigation 93 2379-2386.

Russell ST, Zimmerman TP, Domin BA \& Tisdale MJ 2004 Induction of lipolysis in vitro and loss of body fat in vivo by zinc-alpha2-glycoprotein. Biochimica et Biophysica Acta 1636 59-68.

Sanders PM \& Tisdale MJ 2004 Effect of zinc-alpha2-glycoprotein (ZAG) on expression of uncoupling proteins in skeletal muscle and adipose tissue. Cancer Letters 212 71-81.

Schäffler A, Ehling A, Neumann E, Herfarth H, Tarner I, Schölmerich J, Müller-Ladner U \& Gay S 2003 Adipocytokines in synovial fluid. Journal of the American Medical Association 290 1709-1710.

Senolt L, Pavelka K, Housa D \& Haluzík M 2006 Increased adiponectin is negatively linked to the local inflammatory process in patients with rheumatoid arthritis. Cytokine 35 247-252.

Simons PJ, van den Pangaart PS, van Roomen CP, Aerts JM \& Boon L 2005 Cytokine-mediated modulation of leptin and adiponectin secretion during in vitro adipogenesis: evidence that tumor necrosis factor-alpha and interleukin-1beta-treated human preadipocytes are potent leptin producers. Cytokine 32 94-103.

Stofkova A, Skurlova M, Tybitanclova K, Veselsky L, Zelezna B \& Jurcovicova J 2006 Relationship among nitric oxide, leptin, ACTH, corticosterone, and IL-1beta, in the early and late phases of adjuvant arthritis in male Long Evans rats. Life Sciences 79 2486-2491.

Sugawara K, Miyata G, Shineha R \& Satomi S 2003 The lipolytic responsiveness to endotoxin in subcutaneous adipose tissue is greater than mesenteric adipose tissue. Tohoku Journal of Experimental Medicine 199 171-179.

Tisdale MJ 2004 Cancer cachexia 2004. Langenbeck's Archives of Surgery 389 299-305.

Todorov PT, McDevitt TM, Meyer DJ, Ueyama H, Ohkubo I \& Tisdale MJ 1998 Purification and characterization of a tumor lipid-mobilizing factor. Cancer Research 58 2353-2358.

Tokarczyk-Knapik A, Nowicki M \& Wyros'lak J 2002 The relation between plasma leptin concentration and body fat mass in patients with rheumatoid arthritis. Polskie Archiwum Medycyny Wewnetrznej 108 761-767.

Vara E \& Tamarit-Rodriguez J 1988 Islet secretion of immunoreactive thyrotropin-releasing hormone and the 'paracrine-like' effects of its exogenous administration. Acta Endocrinologica 118 429-436.

Walsmith J, Abad L, Kehayias J \& Roubenoff R 2004 Tumor necrosis factoralpha production is associated with less body cell mass in women with rheumatoid arthritis. Journal of Rheumatology 31 23-29.

Wislowska M, Rok M, Jaszczyk B, Stepien K \& Cicha M 2007 Serum leptin in rheumatoid arthritis. Rheumatology International 27 947-954.

Yasuhara S, Kaneki M, Sugita H, Sugita M, Asai A, Sahani N, Chon JY, Tompkins RG \& Martyn JA 2006 Adipocyte apoptosis after burn injury is associated with altered fat metabolism. Journal of Burn Care and Research 27 367-376.

Zhang B, Berger J, Hu E, Szalkowski D, White-Carrington S, Spiegelman BM \& Moller DE 1996 Negative regulation of peroxisome proliferator-activated receptor-gamma gene expression contributes to the antiadipogenic effects of tumor necrosis factor-alpha. Molecular Endocrinology 10 1457-1466.

\section{Received in final form 15 December 2007 Accepted 8 January 2008 Made available online as an Accepted Preprint 8 January 2008}

